East African Medical Journal Vol. 80 No. 9 September 2003

COMMUNITY AND FACILITY SURVEYS ILLUMINATE THE PATHWAY TO CHILD SURVIVAL IN LIBEN WOREDA, ETHIOPIA

D. Mash, MD, MPH, Senior Child Specialist, Save the Children (USA), 54 Wilton Road Westport, CT 06880 USA, K. Aschenaki, MPH, Health and Child Survival Program Co-ordinator, Save the Children (USA), Ethiopia Field Office, Currently: Country Director, Christian Children Fund Australia, P.O Box 7935, Boroko N.C.D, Papua, New Guinea, T. Kedamo, MD, Health Systems Development Specialist Essential Services for Health in Ethiopia Currently Regional Health Advisor, Horn Sub-region, Save the Children (USA), P.O Box 387, Addis Ababa, Ethiopia, K. Walternsperger, MA, MPH, Africa Regional Health Advisor Save the Children (USA), Currently: Mali Country Representive Helen Keller International, 90 West St. Suite 200, New NY 10006, K. Gebreyes, MD, Department of Emergency Medicine Johns Hopkins Hospital 600 North Wolfe Street, Marburg B-186, Baltimore, MD 211287, O. Pasha, MD, MS, Maternal Child Health Advisor Save the Children USA, 54 Wilton Road Westport CT 06880, USA, and S. Manoncourt, MD, MPH, Lee Medecins Sans Frontieres, Consultant to Save the Children (USA), 54, Wilton Road Westport, CT 06880 USA

Request for reprints to: Dr. O. Pasha, Maternal Child Health Advisor, Save the Children (USA), 54 Wilton Road, Westport, CT 06880, USA

\title{
COMMUNITY AND FACILITY SURVEYS ILLUMINATE THE PATHWAY TO CHILD SURVIVAL IN LIBEN WOREDA, ETHIOPIA
}

\author{
D. MASH, K. ASCHENAKI, T. KEDAMO, K. WALTERNSPERGER, K. GEBREYES, O. PASHA and \\ S. MANONCOURT
}

\begin{abstract}
Objectives: To apply "Pathway to Survival" analysis to baseline assessments to inform integrated management of childhood illness programmes.

Design: A cross-sectional survey evaluating community-based knowledge, practices and coverage and health facility quality.

Setting: Liben Woreda (population 122, 410), a district in Borana Zone, of Ethiopia's Oromia region, from August 1997-Febuary 1998.

Subjects: Three hundred and sixty eight mother-child pairs (age <24 months) seen in the community and 28 children (age $<5$ years) in health facilities.

Results: Of the 368 mothers interviewed $50 \%$ reported that their child was ill in the previous two weeks $(184 / 368)$. Amongst the 101 mothers of children under the age of six months only $24 \%$ reported exclusive breast-feeding (24/101). There were 194 children who should have completed their immunisation schedule; only $17 \%$ of them had done so (33/194). Amongst the 111 children who had diarrhoea, only $17 \%$ had received home treatment with ORS (19/111). Thirty per cent of mothers of children with possible pneumonia (25/83) and $28 \%$ who reported malaria (14/50) sought appropriate care. Amongst those caregivers seen at the health facility only $26 \%$ had an understanding of treatment recommendations.

Conclusions: Based on the pathway to survival analysis, mother's knowledge of illness recognition is limited and they practice both home care and care seeking poorly. Thus few children are likely to receive and comply with standard case management.
\end{abstract}

\section{INTRODUCTION}

The Integrated Management of Childhood illnesses (IMCI) has been recognised as one of the most effective public health approaches for child survival in the developing world (1). IMCI has three components: improving the case management skills of health care workers, strengthening existing health systems and promoting key household and community practices (2). Recognising that childhood illnesses are more prevalent in the developing world and the outcome of illness depends, in large part, on the behaviour of the caregiver, the Basic Support for Institutionalizing Child Survival (BASICS) Project, the United States Agency for International Development (USAID) and the United States Centers for Disease Control and Prevention (CDC) have developed the "Pathway to Survival" a conceptual framework for developing and monitoring integrated case management programmes for child survival $(3,4)$.
This conceptual framework focuses on the behaviour of both the child's caregiver and the health care provider, including the management of illnesses at home, care seeking outside the home, provision of quality health care and compliance with outside treatment $(3,5)$. The behaviours outlined in the framework are modifiable, and associated with mitigating the impact of one or more important public health problems in developing countries (6). One of the uses of the "Pathway to Survival" is to form the basis for an analysis of the deficiencies in childhood illness care in a community. The results of such an analysis can inform the design of an effective programmes for child survival in that community.

In 1997 Save The Children Federation/US started a maternal and child health programme in Liben Woreda (District), Ethiopia. As one of the first steps of this programme we collected baseline data, through 
a population-based quantitative survey, as well as a health facility survey. In this paper we outline both the process and the findings of these efforts in order to demonstrate the utility of such baseline assessment using the "Pathway" to Survival and the use of the results in planning an intervention.

\section{MATERIALS AND METHODS}

Setting: Liben Woreda is the largest district in the Oromia Region in southern Ethiopia. It has an area of $21,800 \mathrm{~km}^{2}$ and in $1997 \mathrm{had}$ an estimated population of 122,410 . The majority of people live in rural areas, employed in agricultural and pastoral activities.

Population-Based Survey: We used a revised Knowledge, Practices and Coverage (KPC) Survey Questionnaire (7), addressing service use and maternal care for diarrhoea, ARI requiring assessment for pneumonia and fever requiring assessment for malaria, as well as socio-economic variables.

A two-stage cluster sampling method was selected. Thirty clusters, probability proportion to size, from a list of peasant associations (kebeles) applying an appropriate sampling interval and a random start and 12-13 households with mother-child pairs within each cluster were selected (8). Two teams were trained and they conducted the interviews in August 1997.

Health Facility Assessment: All the health facilities in Liben Woreda were surveyed. All children under five years of age who presented with diarrhoea or vomiting, and/or fever or malaria and/or difficulty breathing, cough or pneumonia were surveyed. The survey instruments (9), obtained information on key aspects of the knowledge and practices of health workers and of caregivers as they left the health facilities.

The questionnaires were adopted to fit local practices in collaboration with Ministry of Health personnel. The exit interview was administered in Oromifa, the most common language in Liben Woreda. The health worker interview questionnaire was administered in Amharic, the language used by health workers. Two teams collected data over four days (February 1998). Teams attended the entire clinic session, returning in the afternoon for exit interviews for children sent for laboratory investigations (only at Negelle Hospital).

During the clinic visit, the supervisor identified children meeting the inclusion criteria and conducted the facility equipment and supplies assessment. One surveyor conducted health worker observations and the health worker interview at the end of the day; the other conducted exit interviews.

Data Management and 'Pathway to Survival 'Analysis: Data was entered and cleaned in the Integrated MicroComputer Processing System (IMPS) (10) and analysed using Epi-lnfo (version 6.01) (11). Post-entry data verification of one third of the questionnaires confirmed data quality $(99.9 \%$ correct). "Possible pneumonia" was assigned to episodes of cough and difficult or rapid breathing identified by KPC survey (i.e., acute respiratory infections requiring assessment for pneumonia) and accepted "pneumonia" for HF diagnoses.
The prevalence of preventative and illness behaviour was calculated and compared illness prevention, illness recognition, home care, and care seeking between urban and rural populations. The proportions for prevalence of morbidity due to diarrhoea was calculated, ARI needing assessment (possible pneumonia) and fever (possible malaria), as well as for correct home care for diarrhoea (increased breast feeding, increased fluids, increased semi-/solids, ORS, or cereal-based ORT, obviating the need for outside care), care seeking, provision of quality care by the health care provider (the correct medication for an unvalidated diagnosis) and caregiver compliance (as reflected by caregiver understanding of drug dosing instructions) by applying facility-based proportions to the relevant population sample. That is, we applied the quality of care and compliance measures determined at the facility for specific syndromes to the proportion of children whose household caregivers reported seeking care for the given syndrome at $\mathrm{MOH}$ facilities.

\section{RESULTS}

Three hundred and sixty eight mother-child pairs were identified and surveyed during the KPC survey. Eighty per-cent (294/369) of the sample was rural. Reported illness in the prior fortnight was common (111 episodes of diarrhoea (30\%), 83 episodes of cough and fast or difficult breathing (22\%), and 50 episodes of fever (14\%). All six facilities in Liben Woreda were assessed during the health facility survey and found 28 children who initially met the study criteria. Twenty three patients ultimately had unconfirmed diagnoses useful for this analysis, including malaria (10), diarrhoea (5), pneumonia (2), malaria and pneumonia (2), and malaria and diarrhoea (1).

Child illness prevention: The overall child illness prevention behaviours were found to be practiced poorly with differences in the prevalence of these behaviours between the urban and rural populations (Table 1). Late initiation of breast-feeding is common; $46 \%$ of infants receive breast milk for the first time after the second day of life. Exclusive breast-feeding is uncommon. Only $27 \%$ of infants aged four months were breast-fed. Only $51 \%$ of infants $12-23$ months of age are still breast-fed, and only $10 \%$ (28/264) were weaned at an appropriate age. There was no difference between the inhabitants of urban and rural areas in breast-feeding practices. Immunisation coverage of children 12-23 months of age was poor: overall $23 \%$ (44/194) had received measles vaccine: and 17\% (33/ 194) were completely immunized. Infants in urban areas $(44 \%)$ were more likely to be immunised than those in rural $(12 \%)$ areas. 
Table 1

Differences in urban and rural child illness preventive behaviours

\begin{tabular}{lllll}
\hline Indicator & Overall $(\mathrm{n}=368)$ & Urban $(\mathrm{n}=75)$ & Rural $(\mathrm{n}=293)$ & OR (95\%CI) \\
\hline $\begin{array}{l}\text { Initiation of breastfeeding } \\
\text { less than two days after birth }\end{array}$ & $197 / 368(53 \%)$ & $42 / 75(56 \%)$ & $155 / 293(53 \%)$ & $1.1(0.7-2.0)$ \\
$\begin{array}{l}\text { Infants four months or less who } \\
\text { are exclusively breast-fed }\end{array}$ & $19 / 70(27 \%)$ & $3 / 16(19 \%)$ & $16 / 54(30 \%)$ & $0.6(0.1-2.5)$ \\
$\begin{array}{l}\text { Infants six months or less who } \\
\text { are exclusively breast-fed }\end{array}$ & $24 / 101(24 \%)$ & $6 / 23(26 \%)$ & $18 / 78(23 \%)$ & $1.2(0.4-3.9)$ \\
$\begin{array}{l}\text { Infants more than six months } \\
\text { who are weaned appropriately }\end{array}$ & $28 / 267(10 \%)$ & $6 / 52(12 \%)$ & $22 / 215(10 \%)$ & $1.1(0.4-3.2)$ \\
$\begin{array}{l}\text { Infants 12-23 months currently } \\
\text { breast-fed }\end{array}$ & $98 / 194(51 \%)$ & $16 / 32(50 \%)$ & $82 / 162(51 \%)$ & $1.0(0.4-2.2)$ \\
$\begin{array}{l}\text { Infants 12-23 months immunised } \\
\text { against measles }\end{array}$ & $44 / 194(23 \%)$ & $15 / 32(47 \%)$ & $29 / 162(18 \%)$ & $4.1(1.7-9.8)$ \\
$\begin{array}{l}\text { Infants 12-23 months fully } \\
\text { immunised }\end{array}$ & $33 / 194(17 \%)$ & $14 / 32(44 \%)$ & $19 / 162(12 \%)$ & $5.9(2.3-14.9)$ \\
\hline
\end{tabular}

Table 2

Differences in urban and rural illness care practices

\begin{tabular}{|c|c|c|c|c|}
\hline Indicator & Overall $(n=368)$ & $\operatorname{Urban}(\mathrm{n}=75)$ & Rural (n=293) & OR $(95 \% \mathrm{CI})$ \\
\hline \multicolumn{5}{|l|}{ Diarrhoeal Disease } \\
\hline $\begin{array}{l}\text { Child had diarrhoea in } \\
\text { two weeks prior to } \\
\text { the interview }\end{array}$ & $111 / 386(30 \%)$ & $18 / 75(24 \%)$ & $92 / 293(32 \%)$ & $0.7(0.64-1.3)$ \\
\hline $\begin{array}{l}\text { Mother continued to } \\
\text { breast-feed same as or } \\
\text { more than usual }\end{array}$ & $36 / 111(32 \%)$ & $8 / 18(44 \%)$ & $28 / 93(30 \%)$ & $1.9(0.6-5.9)$ \\
\hline $\begin{array}{l}\text { Mother continued to } \\
\text { give other fluids same } \\
\text { as or more than usual }\end{array}$ & $58 / 111(52 \%)$ & $112 / 18(67 \%)$ & $46 / 93(49 \%)$ & $2.0(0.6-6.8)$ \\
\hline $\begin{array}{l}\text { Mother continued to } \\
\text { give solid/semi-solid } \\
\text { food same as or more } \\
\text { than usual }\end{array}$ & $36 / 111(32 \%)$ & $8 / 18(44 \%)$ & $28 / 93(30 \%)$ & $1.9(0.6-5.9)$ \\
\hline $\begin{array}{l}\text { Mother reported } \\
\text { knowing how to } \\
\text { prepare ORS }\end{array}$ & $172 / 368(47 \%)$ & $62 / 75(83 \%)$ & $110 / 293(38 \%)$ & $7.9(4.0-16.0)$ \\
\hline $\begin{array}{l}\text { Mother gave child } \\
\text { ORS during last } \\
\text { episode of diarrhoea }\end{array}$ & $19 / 111(17 \%)$ & $6 / 18(33 \%)$ & $13 / 93(14 \%)$ & $3.1(0.8-11.1)$ \\
\hline $\begin{array}{l}\text { Mother sought care } \\
\text { outside the home }\end{array}$ & $48 / 111(43 \%)$ & $12 / 18(67 \%)$ & $36 / 92(39 \%)$ & $11 / 75(15 \%)$ \\
\hline \multicolumn{5}{|l|}{ Pneumonia } \\
\hline $\begin{array}{l}\text { Mothers reporting } \\
\text { cough and } \\
\text { rapid/difficult breathing }\end{array}$ & $83 / 368(23 \%)$ & $11 / 73(15 \%)$ & $72 / 293(25 \%)$ & $0.5(0.3-11)$ \\
\hline $\begin{array}{l}\text { Mothers report seeking } \\
\text { care outside the home }\end{array}$ & $25 / 83(30 \%)$ & $7 / 11(64 \%)$ & $18 / 72(25 \%)$ & $5.3(1.2-25.0)$ \\
\hline \multicolumn{5}{|l|}{ Malaria } \\
\hline Mothers report malaria & $50 / 368(14 \%)$ & $6 / 75(8 \%)$ & $44 / 293(15 \%)$ & $0.5(0.2-1.3)$ \\
\hline Mothers report seeking & $14 / 50(28 \%)$ & $4 / 6(66 \%)$ & $10 / 43(23 \%)$ & $6.6(0.8-63.9)$ \\
\hline
\end{tabular}


Acute Watery Diarrhoea: Illness Recognition and Home Care: One hundred and eleven mothers (30\%) reported diarrhoea in their children in the fortnight prior to the interview (Table 2). Most, 58\% (64/111) reported that they continued breast-feeding during this episode; however, only a few; 6\% (7/111) reported increasing breastfeeding. Likewise, many gave the same amount of other liquids; 43\% (48/111), but fewer; 9\% (10/111) increased liquids. Fewer still gave the same amount of solids $26 \%$ $(28 / 111)$ or increased them $7 \%(8 / 111)$.

Less than half of the mothers reported knowing how to prepare ORS; $47 \%$ (172/368), and none of these mothers reported giving their child sugar salt solutions or cereal based ORS during the last episode of diarrhoea. A few mothers gave packaged ORS to their children during the last episode of diarrhea; $17 \%$ (19/111). Mothers in urban areas were seven times more likely to report knowing how to make ORS and are also three times more likely to give ORS than mothers in rural areas however, the latter number only reaches marginal statistical significance.

Care Seeking: Forty four per cent (49/111) of the mothers seek care outside the home for their child during the episode of diarrhoea. Women in urban areas; 67\% (12/ 18) are more likely to report seeking care than those in rural areas; 39\% (36/92). Mothers in urban areas reported seeking care at the hospital $(50 \%)$ or a private clinic $(33 \%)$, whereas mothers $(65 \%)$ in rural areas, reported going to a HS.

Pneumonia: Illness Recognition and Care-Seeking: Twenty three per cent (83/368) mothers reported that their child, had cough with rapid or difficult breathing during the two weeks prior to interview. In the urban population only, $15 \%(11 / 75)$ reported these symptoms, compared to $25 \%(72 / 293)$ in the rural areas. Mothers in urban $64 \%(7 / 11)$ areas were more likely to seek care for their children outside the home than mothers in rural areas $25 \%$ (18/72). In the rural areas, respondents were more likely to have visited a HS $(67 \%)$ or a drug vendor $(22 \%)$; whereas, mothers in urban areas sought care from drug vendors $(57 \%)$ or the hospital (29\%), though some did attend a HS (14\%).
Malaria: Illness Recognition: Fifty mothers (14\%) reported that their child had malaria in the last two weeks prior to interview. Only $8 \%(6 / 75)$ of the mothers residing in urban areas reported malaria; however, in rural areas $15 \%$ (44/293) of mothers reported malaria in their children. Fifty mothers were asked about the signs and symptoms of malaria; $13(26 \%)$ recognised fever as a symptom, 10 (20\%) recognised sweating and shivering, but only three to five mothers knew arthralgias, headache, diarrhoea/vomiting or anorexia. On the other hand, a larger number knew the central nervous system signs of severe malaria, such as convulsions; $38 \%(19 / 50)$ and loss of consciousness (28\% (14/50).

Health Facility Assessment: Twenty three of the 28 children observed at the health facility were eligible for inclusion in the analysis; Six $(21 \%)$ had diarrhoea, four (14\%) had pneumonia and thirteen $46 \%$ had malaria. ORS for diarrhoea and appropriate medications for pneumonia and malaria were correctly prescribed to $91 \%$ $(21 / 23)$ of the children and the treatment was explained to $74 \%(17 / 23)$ of the caregivers. However, only $13 \%$ $(3 / 23)$ of the caregivers were given instructions about follow-up and only $4 \%(1 / 23)$ had the opportunity to ask questions. The health workers incorrectly prescribed antibiotics to almost all of the children with diarrhoea, $83 \%(5 / 6)$ and gave a demonstration of ORS use to one caregiver only.

Not surprisingly, caregiver knowledge at exit interview was limited; only $26 \%(6 / 23)$ of the caregivers knew the correct doses or frequency of the drugs. Seventy per cent $(16 / 23)$ of the caregivers knew at least one sign which would prompt them to return to the health facility.

Referral: We did not seek illness-specific referral practices. Half (3/6) of providers knew at least three indications for child referral, and most (5/6) reported inability to refer due to patient refusal, lack of transport, and especially lack of money. Indeed, we observed the family of a child with signs of severe pneumonia refuse referral because of the belief that the child would die as he did three hours later.

\section{Figure 1}

Morbidity rates, care seeking, quality of care and likely compliance by disease based on the "Pathway to Survival" Diarrhoea

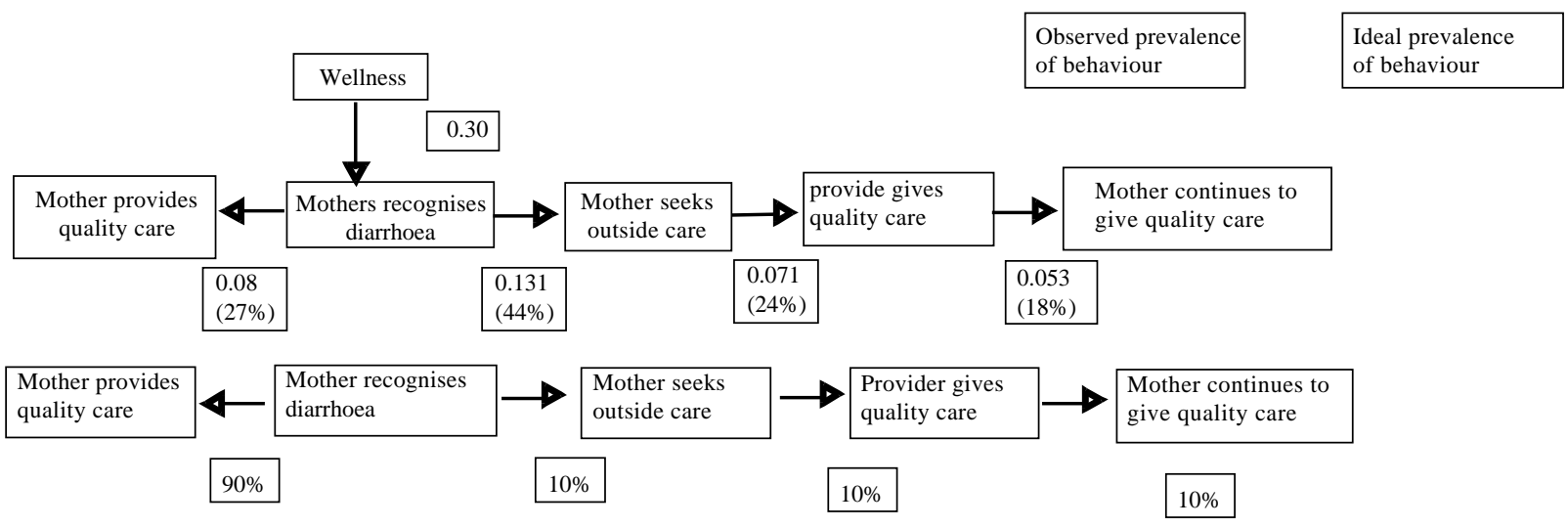


Figure 2

Morbidity rates, care seaking, quality of care and likely compliance by disease based on the "Pathway to Survival" "Malaria" (Fever)

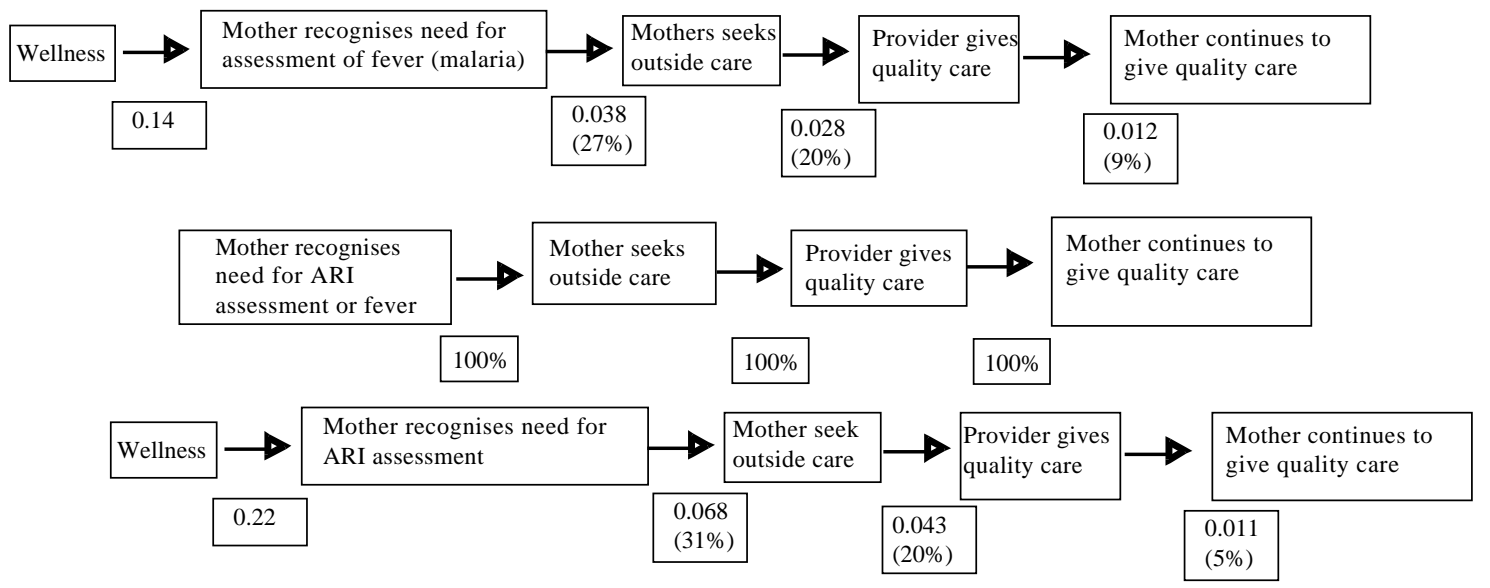

Pathway Analysis (Figure 1): Thirty per cent of children had episodes that were recognised by the mother as diarrhoea in the two weeks preceding the study. Amongst these, only $27 \%$ received quality care from the caregiver within the home. In contrast, $43 \%$ of the caregivers sought outside care for their child including 28\% who sought care from the $\mathrm{MOH}$ facility. Amongst those seeking care at the MOH facility, 24\% received good quality care including appropriate medication and counseling and at exit interview only $18 \%$ of the caregivers were able to describe the care that they needed to give the child. This is in contrast to the gold standard of care for diarrhoea in a developing country setting, where the majority of children should receive home care that is sufficient to obviate the need for outside care while the remainder should be brought to a facility and receive good quality care with which the caregiver is compliant.

Twenty two per cent (83/368) of the children had symptoms that required assessment for ARI but only $30 \%(25 / 83)$ of these mothers sought outside care $19 \%$ (16/83) at MOH facility. Amongst those seeking care at the MOH facility, only $20 \%$ received good care, and only $5 \%$ were able to describe at exit interview the correct steps in providing care. Similar numbers were found for the $14 \%$ of children with fever, who required assessment for malaria. Amongst these, $28 \%$ were taken for outside care (21\% at MOH facility), $20 \%$ received good care at the facility, and only $9 \%$ of the caregivers could describe appropriate care at exit interview. This is in contrast to accepted standards for care of a child with symptoms of ARI needing assessment or with fever for which $100 \%$ of the children should be brought to a facility and receive good quality care with which the caregiver complies.

\section{DISCUSSION}

The population of Liben Woreda practice key health behaviours poorly. Their knowledge of important facts is limited and their utilisation of formal health care services is inappropriate. Fifty two per cent of mothers in rural areas reported that their children had been sick in the previous two weeks compared to $41 \%$ of their urban counterparts. Mothers in rural areas were less likely to seek outside care for their children during episodes of possible pneumonia or fever than mothers in urban areas and they were less likely to give appropriate home care for children with diarrhoea. Given that the majority of the population in Liben Woreda lives in rural areas, the differences in illness and health behaviours between the urban and rural areas these findings were all the more important. Indeed, SC/US's child health programme seeks to address the health needs of children in rural areas.

Our study was not designed to identify the onset of disease; thus, we could not get information regarding the timeliness of illness recognition. However, the results for home care of diarrhoea were disappointingly poor; less than $10 \%$ of the children received optimal home care for diarrhoea; $8 \%$ had appropriate nutritional management and only $17 \%$ reported ORT use. Not surprisingly, care seeking for diarrhoea is excessive. Interestingly, amongst the 19 mothers who gave ORT, 17 (89\%) sought outside care, a considerably larger proportion than those who did not give ORT $31 / 91$; (34\%). This suggests that most mothers who use ORT do so at the recommendation of a health care provider rather than doing so themselves at home. Thus we may have overestimated the number of children receiving appropriate home care for diarrhoea, as our study did not assess the sequence of events during the illness episode. 
Only $27 \%$ and $31 \%$ of the caregivers of children with possible pneumonia and malaria, respectively, sought care at health facilities. Both of these conditions require antimicrobial treatment. The quality of care received in the interactions we observed was mixed. Providers selected appropriate treatment; however they gave weak counseling which could hinder transmission of critical dosing information, particularly for potentially life-saving antibiotics. Thus, compliance is likely to have been low.

We combined key child health findings from both surveys (Figure 1). During the fortnight survey $30 \%$ of the children under age 24 months in Liben Woreda experienced an episode of diarrhoea, $22 \%$ had episodes of symptoms requiring assessment for acute respiratory infection (ARI), and 14\% had fever requiring assessment for malaria. A small fraction of these, only $13 \%$ (18\% diarrhoea, 5\% ARI, and 9\% malaria), are likely to have received and complied with good quality care. Scarce health services are over-utilised for diarrhoea and under-utilised for possible pneumonia and malaria. $\mathrm{MOH}$ providers select the correct treatment but are ineffective in explaining its administration at home resulting in poor caregiver compliance.

Given these findings, the response of the health system in Liben should include measures to improve: (i) preventive health services (immunisations), practices (breast feeding and nutrition), and knowledge (danger signs); (ii) home care for diarrhoea to reduce careseeking; (iii) access to pneumonia and malaria case management; and (iv) provider communication skills to enhance the efficacy of case management and followup on home care.

There is an urgent need for better prevention through outreach clinics for immunisations and through innovative strategies to educate the populace in healthier behaviour. A complementary strategy to increase service availability involves dialogue with $\mathrm{MOH}$ regarding pilot-testing community pharmacies or registered pharmacists to dispense first-line medications for pneumonia and malaria without prescription after proper case management training, including counseling. Community-based revolving funds for emergency transport would make available services more geographically accessible. Prevention and more available high quality services will decrease the number of untreated or improperly treated children.

As in this example in Liben, the Pathway can be used as a tool for measuring strengths and weaknesses in childhood illness management, including problems of home care, care seeking, quality of care and compliance (3). To date local assessments that have been performed using this approach have focused on mortality analysis. In Bolivia, 271 households were identified where a child under the age of five years had died. A verbal autopsy instrument was used to reconstruct the events leading up to the death and information gathered was used to carry out Pathway analysis. A two-stage process was used: initially Pathway indicators were identified from the quantitative and qualitative data, and then a panel of physicians reviewed each case and identified "breakdowns" in the Pathway. The majority of deaths here were attributed to poor illness recognition and inappropriate care-seeking behaviour (12). The length of time between recognition of illness and the child's death was short; $53 \%$ of the children died within a day of their caregiver recognising that they were ill, and the majority of children (80\%) were dead by the fifth day after recognition of illness. This would suggest that caregivers only recognised severe or advanced childhood illness. Similarly, 62\% of the children who died never received treatment from a formal health care provider (public health center, private practitioner or hospital).

Other studies that have sought to explore deficiencies in childcare using the "Pathway to Survival" have used similar verbal autopsy methods. Death reviews are critical to identify specific factors that contribute to cases that go woefully wrong. On the other hand, a study of mortal outcomes is likely biased towards including atypical situations, such as children with disabilities or failure to thrive, family impoverishment from repeated child illness, or parental exhaustion from frenetic care seeking. Moreover, reported practices may be invalid due to caregiver guilt or grief or duration of recall. Our study of a random sample of families with surviving children circumvents these concerns. To our knowledge, ours is the first study that combines the use of a health facility and household survey to inform the Pathway. We believe that this approach can add to the previously described methods for evaluating childcare practices and provide insights that focus interventions.

Our methodology has some limitations; (i) The low health facility utilisation impaired statistical power but provided sufficient numbers for planning; (ii) We did not investigate the private sector, (iii) Compliance was inferred rather than measured. In fact, the inferences were probably conservative. Without knowledge of instructions, adherence to them seems unlikely; (iv) The children in our study all survived despite concerns at most steps along the pathway. There may have been some well or mildly ill children who were reported as ill perhaps because of an expectation of benefit from the interviewer.

We applaud the latest version of the Pathway model, which includes a middle 'community band' between the household and the facility levels. However the current "Pathway to Survival" provides an incomplete organising framework. Designed as a tool for the intergrated Management of Childhood Illness, it omits maternal care. Findings from the Liben KPC survey also showed that illness prevention for maternal health is sub-optimal. Seventy eight per cent of the mothers are not appropriately immunised. Only 5\% of the mothers practice modern family planning. The health 
facility assessment tool, however, only assessed IMCI; thus we were unable to include maternal care in our Pathway analysis (13). Another remaining need is to further stress the promotive and preventive behaviours in addition to those responding to illness (14). A community and facility-based survey and a Pathway analysis for both maternal and child health, providing a balance of care before and after illness, holds the promise of uncovering factors that reduce child mortality both directly and indirectly through enhanced maternal and perinatal survival.

\section{REFERENCES}

1. World Bank. The Office of The Publisher (Editor). World Development Report 1993: Investing in Health. New York: Oxford University Press; 1993.

2. Tulloch, J. Integrated approach to child health in developing countries. Lancet. 1999; 354;: (Suppl.2) S1116-S1120.

3. Waldman, R. Bartlett, A.V. Campbell, C.C., and Steketee, R.W. Overcoming remaining barriers: the pathway to survival. Arlington VA.: BASICS. Current issues in child survival series. 1996; 1-12.

4. Claeson, M. and Waldman, R.J. The evolution of child health programmes in developing countries: from targeting diseases to targeting people. Bull. World Health Org. 2000; 78:1234-1245.

5. Waldman, R., BASICS' Framework for Action: The Pathway to Survival, Child Survival BASICS, Arlington USA: BASICS, 1995.

6. Murray, J; Adeyi, G.N; Graeff, J., et al. Emphasis Behaviors in Maternal and Child Health: Focusing on Caregiver Behaviors to Develop Maternal and Child Health Programs in Communities. Arlington USA, BASICS. 1997.
7. Newberry, D., and W. Weiss, (editors) Survey Trainer's Guide for PVO Child Survival Project Rapid Knowledge, Practice and Coverage (KPC) Surveys, Baltimore USA: Johns Hopkins University School or Hygiene and Public Health and PVO Child Survival Support Program, July 1995.

8. United Nations Children's Fund, Monitoring Progress Toward the Goals of the World Summit for Children - a Practical Handbook for Multiple-Indicator Surveys, New York: Planning and Evaluation and Research Offices, Programme Division, UNICEF, January 1995.

9. Murray, J. and S. Manoncourt, Integrated Health Facility Assessment Manual. Using Local Planning to Improve the Quality of Child Care at Health Facilities. Arlington USA: BASICS. 1998.

10. Integrated Microcomputer Processing System (IMPS), version 3.1, International Statistical Programs Center, U.S. Bureau of the Census, Washington, DC: (undated).

11. Dean, A.G: Dean, J.A., Burton, A.H, and Dicker, R.C, Epi Info, Version 5: a word processing, database and statistics program for epidemiology on micro-computers. USA, Incorporated, Stone Mountain, Georgia. 1990.

12. Aguilar, A.M., Alvarado, R., Cordero, D., Kelly, P., Zamora, A., and Salgado, R. Mortality Survey in Bolivia: The Final Report. Investigating and Identifying the Causes of Death in Children Under Five. Published for the USAID by the Basic Support for Institutionalizing Child Survival (BASICS) Project. Arlington, VA. 1998.

13. Winch, P., LeBan, K., and Kusha, B., Reaching Communities for Child Health and Nutrition: A Framework for Household and Community IMCI, Calverton, MD: Child Survival Technical Support. 2001.

14. Becker S., and Black R.E., A Model of Child Morbidity, Mortality and Health Interventions. Population and Development Review. 1996; 22:431-456. 